\title{
Discussion
}

Dubai Medical

Journal

\section{COVID-19 Pandemic along with Pandemic of Lifestyle-Associated Diseases Victimizes Patients in an Inflammation Context!}

\author{
Ali Saeedi-Boroujeni ${ }^{a}$ Mohammad-Reza Mahmoudian-Sanib \\ a Department of Immunology, Faculty of Medicine, Ahvaz Jundishapur University of Medical Sciences, Ahvaz, Iran; \\ ${ }^{b}$ Thalassemia and Hemoglobinopathy Research Center, Health Research Institute, Ahvaz Jundishapur University of \\ Medical Sciences, Ahvaz, Iran
}

The 2019 novel coronavirus (2019-nCoV) is undoubtedly one of the most complex viruses that have ever challenged humanity. On March 11, 2020, at a press conference, the World Health Organization declared coronavirus disease 2019 (COVID-19) a pandemic as cases of COVID-19 confirmed outside China were increased by 13 times and the number of affected countries was increased threefold. On that day, 126,000 people around the world became infected with COVID-19, and 122 countries reported people with the infection. The $2019-\mathrm{nCoV}$ infected more than 4,101,992 people and killed 280,454 people in over 212 countries (May 10, 2020) [1, 2]. According to the phylogenetic tree, $2019-\mathrm{nCoV}$ is closer to bat coronaviruses, such as bat SARS-like coronavirus ZXC21 (bat-SL-CoV ZXC21) and bat SARS-like coronavirus ZC45 (bat-SL-CoV-ZC45), and is more distant from severe acute respiratory syndrome coronavirus (SARS-CoV). Sequencing from 5 patients showed that the genome sequence of 2019-nCOV had $96 \%$ similarity with the bat coronavirus $[3,4]$, which spread to 29 countries in 2002 from China as the country of origin and killed 744 people [5]. The 2019-nCoV belongs to the betacoronaviruses and is able to develop COVID-19 infection through involvement of the upper and lower respiratory tract with severe respiratory syndrome. The infection rate of $2019-\mathrm{nCoV}$ is much higher than that of SARS-CoV. Although the genome sequence of the novel

\begin{tabular}{ll}
\hline KARGER & (c) 2020 The Author(s) \\
& Published by S. Karger AG, Basel \\
& This article is licensed under the Creative Commons Attribution- \\
karger@karger.com & NonCommercial-NoDerivatives 4.0 International License (CC BY- \\
NC-ND) (http://www.karger.com/Services/OpenAccessLicense). \\
Usage and distribution for commercial purposes as well as any dis- \\
tribution of modified material requires written permission.
\end{tabular}

coronavirus has been rapidly identified, the mechanism of its pathogenesis remains a puzzle with many missing fragments [6]. In general, patients $>65$ years with underlying diseases are at much greater risk of death. Acute respiratory distress syndrome (ARDS) and acute lung injury (ALI) caused by the cytokine storm have been identified as the leading cause of death for the patients with COVID-19 [7]. Studies have shown that the lungs of patients with this infection are full of activated inflammatory macrophages with high expression of inflammatory chemokines that trigger the recruitment of immune cells to the lung tissue. This neutrophilic inflammation also has a prominent presence and can exacerbate the damage. As happens in SARS-CoV and middle east respiratory syndrome (MERS), the cytokine storm causes a severe immune system attack, causing ARDS and multiple organ failure and eventually leading to death in severe cases of SARS-CoV-2 infection. The SARS-CoV-2 proliferation in a wide range of cells could be in line with the many observations based on direct and indirect activation of NACHT, LRR and PYD domains-containing protein 3 (NALP3) inflammasomes by other betacoronaviruses. The activation of NLRP3 inflammasome may develop the severe cytokine storm, which subsequently causes ARDS and multiple organ failure and eventually patient death. ARDS in the acute phase causes alveolar edema, interstitial inflammation, lung tissue growth, and decreased lung

Mohammad-Reza Mahmoudian-Sani

Thalassemia and Hemoglobinopathy Research Center Health Research Institute, AJUMS

Golestan Avenue, Ahvaz 61357-15794 (Iran)

mohamadsani495@gmail.com 
capacity $[8,9]$. ARDS and ALI are often characterized by the neutrophil accumulation in the lungs and increased production of inflammatory cytokines, chemokines, proteases, and oxidants. The inflammasome is an integral and key part of the innate immune system. The NLRP3 inflammasome is a recently recognized key innate immune receptor in the induction of ADRS/ALI. Recent studies show that SARS-CoV has a high structural similarity to 2019-nCoV and can cause inflammasome activation in different ways $[10,11]$. Cytokines are dangerous double-edged swords used by the coronaviruses in the worst possible way. Proinflammatory cytokines protect the host cells against the invasion of pathogens but are also capable of initiating pathological inflammation [12]. Inflammatory responses can cause virus replication and reduce infection, but inflammation has also been able to spread a large number of viruses, as well as spreading viral infection to cells such as macrophages that spread the virus to other host tissues and organs. The latest structural models of mature 2019-nCoV peptides produced by Contact-guided Iterative Threading ASSEmbly Refinement (C-I-TASSER) clearly show that 2019-nCoV, responsible for COVID-19, encodes NLRP3 inflammasome-activating proteins [13]. Thanks to advances in medical and public health in recent decades, human life expectancy has prolonged dramatically over the last 100 years, but this increase in life expectancy has been associated with an increase in some diseases. Lifestyle change in recent years developed diseases such as type 2 diabetes, obesity, and chronic liver disease. Key risk factors for these diseases include Western-pattern diet, such as high-calorie, high-sugar foods, trans-unsaturated fats, salts, and food additives, but instead reduced carbohydrates, fiber, vitamins, and minerals [14]. With more than one-third of adults around the world suffering from overweight or obesity, we are experiencing a pandemic of lifestyle-associated diseases [15]. It has been proven that there is a type of chronic inflammation called metainflammation in overweight people. This chronic inflammation is a major cause of the development of obesity in a wide range of metabolic syndrome-related disorders [16]. A network of specialized immune cells plays a role in the formation and exacerbation of this type of inflammation. Previous studies have shown the presence of a cause-effect relationship between Western-pattern diet and the composition of the human gut microbiota. These studies have shown that this diet can cause quantitative and qualitative changes in the gut microbiota population and their metabolites, called dysbiosis [17]. Since the activity of immune cells in that region is constantly affected by these microorgan- isms, any changes in the molecules and metabolites in that region can overshadow the immune responses. On the other hand, the Western-pattern diet may cause disruption of and consequently destroy the integrity of mucosal surfaces of the gastrointestinal tract. Failure to maintain the integrity of gastrointestinal mucosal surfaces along with dysbiosis can cause the penetration of microbial destructive products into the portal vein flow and thus the induction of inflammation. Pore formation in the intestinal epithelium, in addition to the previously mentioned destructive effects, also disrupts immune cell signals, resulting in the penetration of inflammatory myeloid cells in the region, increasing the differentiation of resident gut macrophages from the tolergenic to the inflammatory state and resulting in the loss of useful regulatory $\mathrm{T}$ cells [18]. Recent studies have unveiled a new concept. These studies have focused on the fact that inflammation is not necessarily a transient process and can have long-term effects through the induction of a phenomenon known as trained immunity [19]. Recent findings have shown that the innate immune system also possesses features such as immunological memory in re-contact with pathogens, which is typically attributed to the adaptive immune system. The innate immune cells, such as myeloid cells, can remember the history of inflammation, and act more sensitive and precise in subsequent exposures. The trained immunity occurs due to the longterm effects of epigenetic and metabolic modifications of innate immune cells and their precursors, resulting in nonspecific responses to pathogens [20]. Recent research in rats has shown that Western lifestyle triggers systemic inflammatory responses and induces long-lasting immune changes, leading to stronger responses in the second exposure. Interestingly, the Western-pattern diet produces environmental risk signals, such as cholesterol crystals and uric acid, which are recognized by a key innate immunity sensor, the NLRP3 inflammasome. Through these sensors, the myeloid cell precursors undergo changes that induce inflammation. Other studies in rats have shown that the Western-pattern diet can increase the myeloid cell production and induce the phenomenon of trained immunity in these differentiated cells and even their precursors. Accordingly, a harmful diet can be detected by the immune system as a threat, like a pathogen. Therefore, improving healthy living by promoting effective preventive measures as well as new therapeutic measures to prevent the emergence of non-communicable diseases and vulnerability to pandemics such as COVID-19, which are the core of systemic and destructive inflammation, should be one of the immediate
56

Dubai Med J 2020;3:55-57 DOI: $10.1159 / 000508552$
Saeedi-Boroujeni/Mahmoudian-Sani 
goals of public healthcare efforts. This study and many other studies show that it is imperative to seriously reconsider our lifestyle and diet. If we care about our health and that of our family, we must seriously avoid eating highcalorie, high-salt, fast-food, and unproductive foods and we need to increase the longevity and quality of life for ourselves and our families by replacing them by healthy foods. Several clinical trials, such as Primary Prevention of Cardiovascular Disease with a Mediterranean Diet (PREDIMED), Indian and Mediterranean diet study, and the Canakinumab Anti-Inflammatory Thrombosis Outcome Study (CANTOS) trial have provided encouraging results, which suggest conceivable reduction and treatment of lifestyle-associated chronic inflammatory diseases. According to research in COVID-19 patients and animal studies, destructive inflammation, in particular the overactivation of NLRP3 inflammasome by the virus, played a major role in the development of the most severe form of the disease as a cause of virus-related mortality. Not only COVID-19, but also varieties of diseases ranging from cancer to autoimmune disorders as well as uncontrolled immune responses are the major contributors to the damage of severe immune responses to infectious agents. Therefore, proper lifestyle and nutrition by maintaining the homeostasis of immune responses not only protects a human body against the risk of many of our future non-communicable chronic diseases, but also reduces the risk of morbidity and mortality due to unexplained inflammation in the event of epidemics and pandemics such as SARS-CoV2.

\section{Statement of Ethics}

This article does not contain any studies with human participants or animals performed by any of the authors.

\section{Disclosure Statement}

The authors declare that they have no conflicts of interest to disclose.

\section{References}

1 Guan WJ, Ni ZY, Hu Y, Liang WH, Ou CQ, He JX, et al.; China Medical Treatment Expert Group for Covid-19. Clinical characteristics of coronavirus disease 2019 in China. N Engl J Med. 2020 Apr;382(18):1708-20.

2 WHO. Coronavirus disease 2019 (COVID-19): situation report, 59. 2020. Available from: https://apps.who.int/iris/handle/10665/ 331597.

3 Chen Y, Liu Q, Guo D. Emerging coronaviruses: genome structure, replication, and pathogenesis. J Med Virol. 2020 Apr;92(4): 418-23.

4 Wu F, Zhao S, Yu B, Chen YM, Wang W, Song ZG, et al. A new coronavirus associated with human respiratory disease in China. $\mathrm{Na}$ ture. 2020 Mar;579(7798):265-9.

5 Bolles M, Donaldson E, Baric R. SARS-CoV and emergent coronaviruses: viral determinants of interspecies transmission. Curr Opin Virol. 2011 Dec;1(6):624-34.

6 Zhou P, Yang XL, Wang XG, Hu B, Zhang L, Zhang W, et al. A pneumonia outbreak associated with a new coronavirus of probable bat origin. Nature. 2020 Mar;579(7798):270-3.

7 Mehta P, McAuley DF, Brown M, Sanchez E, Tattersall RS, Manson JJ; HLH Across Speciality Collaboration, UK. COVID-19: consider cytokine storm syndromes and immunosuppression. Lancet. 2020 Mar;395(10229): 1033-4.
8 Li D, Ren W, Jiang Z, Zhu L. Regulation of the NLRP3 inflammasome and macrophage pyroptosis by the $\mathrm{p} 38 \mathrm{MAPK}$ signaling pathway in a mouse model of acute lung injury. Mol Med Rep. 2018 Nov;18(5):4399-409.

9 Lin L, Xu L, Lv W, Han L, Xiang Y, Fu L, et al. An NLRP3 inflammasome-triggered cytokine storm contributes to Streptococcal toxic shock-like syndrome (STSLS). PLoS Pathog. 2019 Jun;15(6):e1007795.

10 Nieto-Torres JL, DeDiego ML, VerdiáBáguena C, Jimenez-Guardeño JM, ReglaNava JA, Fernandez-Delgado R, et al. Severe acute respiratory syndrome coronavirus envelope protein ion channel activity promotes virus fitness and pathogenesis. PLoS Pathog. 2014 May; 10(5):e1004077.

11 Nieto-Torres JL, Verdiá-Báguena C, JimenezGuardeño JM, Regla-Nava JA, Castaño-Rodriguez C, Fernandez-Delgado R, et al. Severe acute respiratory syndrome coronavirus $\mathrm{E}$ protein transports calcium ions and activates the NLRP3 inflammasome. Virology. 2015 Nov;485:330-9.

12 Zhao C, Zhao W. NLRP3 Inflammasome-A Key Player in Antiviral Responses. Front Immunol. 2020 Feb;11:211.

13 Ekins S, Mottin M, Ramos PR, Sousa BK, Neves BJ, Foil DH, et al. Déjà vu: Stimulating Open Drug Discovery for SARS-CoV-2. Drug Discov Today. 2020 Apr;S1359-6446(20)30145-8.
14 Herradon G, Ramos-Alvarez MP, Gramage E. Connecting metainflammation and neuroinflammation through the PTN-MK-RPTP $\beta / \zeta$ axis: relevance in therapeutic development. Front Pharmacol. 2019 Apr;10:377.

15 Christ A, Latz E. The Western lifestyle has lasting effects on metaflammation. Nat Rev Immunol. 2019 May;19(5):267-8.

16 Romantsova TR, Sych YP. Immunometabolism and metainflammation in obesity. Obes Metab. 2019;16(4):3-17.

17 Escobedo G, López-Ortiz E, Torres-Castro I. Gut microbiota as a key player in triggering obesity, systemic inflammation and insulin resistance. Rev Invest Clin. 2014 Sep-Oct; 66(5):450-9.

18 Lazar V, Ditu LM, Pircalabioru GG, Gheorghe I, Curutiu C, Holban AM, et al. Aspects of gut microbiota and immune system interactions in infectious diseases, immunopathology, and cancer. Front Immunol. 2018 Aug;9:1830.

19 Netea MG, Domínguez-Andrés J, Barreiro LB, Chavakis T, Divangahi M, Fuchs E, et al. Defining trained immunity and its role in health and disease. Nat Rev Immunol. 2020 Mar. Epub ahead of print.

20 Netea MG, Joosten LA, Latz E, Mills KH, Natoli G, Stunnenberg HG, et al. Trained immunity: A program of innate immune memory in health and disease. Science. 2016 Apr; 352(6284):aaf1098. 